\title{
n-Butyl Cyanoacrylate Synthesis. A New Quality Step Using Microwaves
}

\section{Yaquelin Ramos Carriles ${ }^{1, *}$, Rubén Álvarez Brito ${ }^{1}$, Ricardo Martínez Sánchez ${ }^{2}$, Elayma Sánchez Acevedo ${ }^{1}$, Paola Rodríguez Domínguez ${ }^{1}$ and Wolf-Dieter Mueller ${ }^{3}$}

1 Chemistry-Physics Department, Faculty of Chemistry, University of Havana, Zapata and G, Vedado, Havana 10400,Cuba; E-Mails: ruben@fq.uh.cu (R.Á.B.); elayma_sanchez@fq.uh.cu (E.S.A.); paola_rodriguez@fq.uh.cu (P.R.D.)

2 Polymers Laboratory, IMRE, University of Havana, Zapata and G, Vedado, Havana 10400, Cuba; E-Mail: ricardo@imre.oc.uh.cu

3 Charité-Universitaetsmedizin Berlin, Assmannshauser Str.4-6, Berlin 14197, Germany; E-Mail: Wolf-Dieter.Mueller@charite.de

* Author to whom correspondence should be addressed; E-Mail: yaquelin@fq.uh.cu; Tel.: +537-878-0684; Fax: +537-837-5774.

Received: 4 April 2014; in revised form: 5 May 2014 / Accepted: 13 May 2014 / Published: 15 May 2014

\begin{abstract}
Alkyl cyanoacrylates are interesting products for use in industry because of their properties enabling them to stick together a wide range of substrates. $n$-Butyl cyanoacrylate is one of the most successfully used tissue adhesives in the field of medicine because it exhibits bacteriostatic and haemostatic characteristics, in addition to its adhesive properties. At present, its synthesis is performed with good yields via Knoevenagel condensation using conventional sources of heating, but this requires a long processing time. The aim of this work was to look for a new way of synthesising $n$-butyl cyanoacrylate using microwave irradiation as the source of heating. This non-conventional source of heating most likely reduces the process time of the synthesis. In comparison with a conventional heating source, such as an oil bath, the results showed the advantages of this method whereby the $n$-butyl cyanoacrylate gave the same yield and quality with a reduction in the reaction time by a factor of 3-5-fold.
\end{abstract}

Keywords: $n$-butyl cyanoacrylate; poly ( $n$-butyl cyanoacrylate); microwaves irradiation 


\section{Introduction}

Alkyl cyanoacrylates (CA) were discovered in the 1940s as a result of research on transparent polymer materials for military use [1]. These products have the property of enabling a wide range of substrates to stick together and are therefore very interesting for industrial applications. Some of them have, moreover, a huge impact in the medicine field. $n$-Butyl cyanoacrylate (BCA) is one of the most successfully used tissue adhesives [2-6], because it provides great tension resistance with bacteriostatic and haemostatic characteristics [7,8]. It is also used as precursor for nanoparticle preparations for controlled delivery of drugs [9-11].

The most commonly applied synthesis of CA is the Knoevenagel condensation between the corresponding alkyl cyanoacetate and formaldehyde in the presence of a basic catalyst and a solvent capable of removing the condensation water by azeotropic distillation. The monomer is not formed in one step, but is instead obtained from the pyrolysis of the corresponding alkyl polycyanoacrylate (PCA). Two procedures are possible to achieve this aim, namely the direct pyrolysis of the oligomer mixture (the most common approach), or the isolation and purification of the mixture previous to its pyrolysis [12-14]. In this work, these procedures are termed "direct synthesis" and "indirect synthesis", respectively. Conventional sources of heating have been used for these syntheses. Although the yields are high, the reaction times required to attain them are quite long.

Microwave irradiation is a non-conventional heating source used in many organic syntheses because it frequently provides a considerable reduction in the reaction time. One example of organic synthesis assisted by microwaves, is the Knoevenagel condensation, and the results are very good [15-17]. Moreover, some of these reactions are eco-friendly too, because they are carried out using inorganic supports that can be reused in other reaction cycles and avoid the use of solvents [18-20].

The aim of this work was to synthesize BCA using microwave irradiation, and to compare the results with those obtained from a classical synthesis using an oil bath.

\section{Results and Discussion}

The BCA synthesis occurs in three steps. In the first, the monomer is obtained, but it polymerizes and oligomers are formed due to the conditions of the reaction medium (second step).

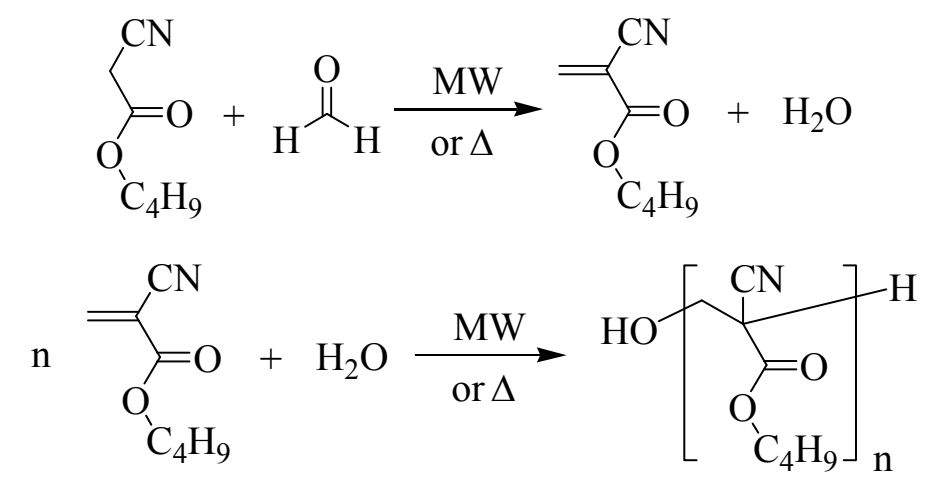

Consequently, the third step is intended to depolymerize the oligomers previously obtained: 


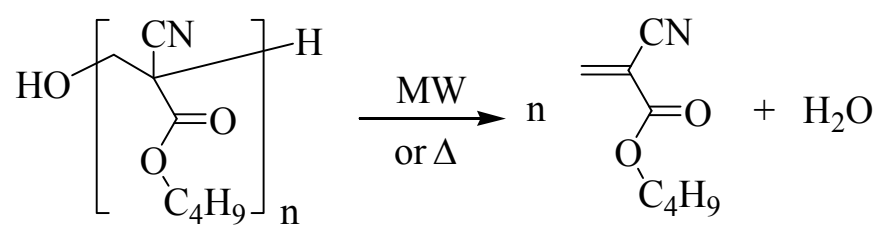

One can see in Table 1 the results obtained in the "direct synthesis" using an oil bath, whose stages are represented in Figure 1. Table 1 also includes the values of the results through the use of a microwave oven, which diminishes the duration of the "direct synthesis".

Table 1. Results of BCA direct synthesis by an oil bath and by a microwave oven. Exp. $=$ Experiments.

\begin{tabular}{|c|c|c|c|c|c|c|c|}
\hline \multirow{2}{*}{ Heating Source } & \multirow{2}{*}{ Exp. } & \multicolumn{4}{|c|}{ Time (min) } & \multirow{2}{*}{$\begin{array}{c}\text { Total Time } \\
(\mathrm{min})\end{array}$} & \multirow{2}{*}{$\begin{array}{l}\text { Monomer } \\
\text { Yield (\%) }\end{array}$} \\
\hline & & 1st Stage & 2nd Stage & 3th Stage & 4th Stage & & \\
\hline \multirow{3}{*}{ Oil bath } & 1 & 40 & 36 & 60 & 23 & 159 & 72 \\
\hline & 2 & 48 & 17 & 57 & 17 & 139 & 63 \\
\hline & 3 & 40 & 43 & 87 & 20 & 190 & 67 \\
\hline \multirow[t]{2}{*}{ Mean values } & & & & & & $163 \pm 26$ & $67 \pm 5$ \\
\hline & 1 & 24 & - & 15 & - & 39 & 72 \\
\hline \multirow[t]{2}{*}{ Microwave oven } & 2 & 9 & - & 38 & - & 47 & 63 \\
\hline & 3 & 10 & - & 27 & - & 37 & 61 \\
\hline Mean values & & & & & & $41 \pm 5$ & $65 \pm 6$ \\
\hline
\end{tabular}

Figure 1. $n$-Butyl cyanoacrylate synthetic stage sequence when using oil bath heating $(\Delta)$. $\mathrm{BCAN}=n$-butyl cyanoacetate, $\mathrm{PF}=$ paraformaldehyde, $\mathrm{PipH}=$ piperidine hydrochloride .

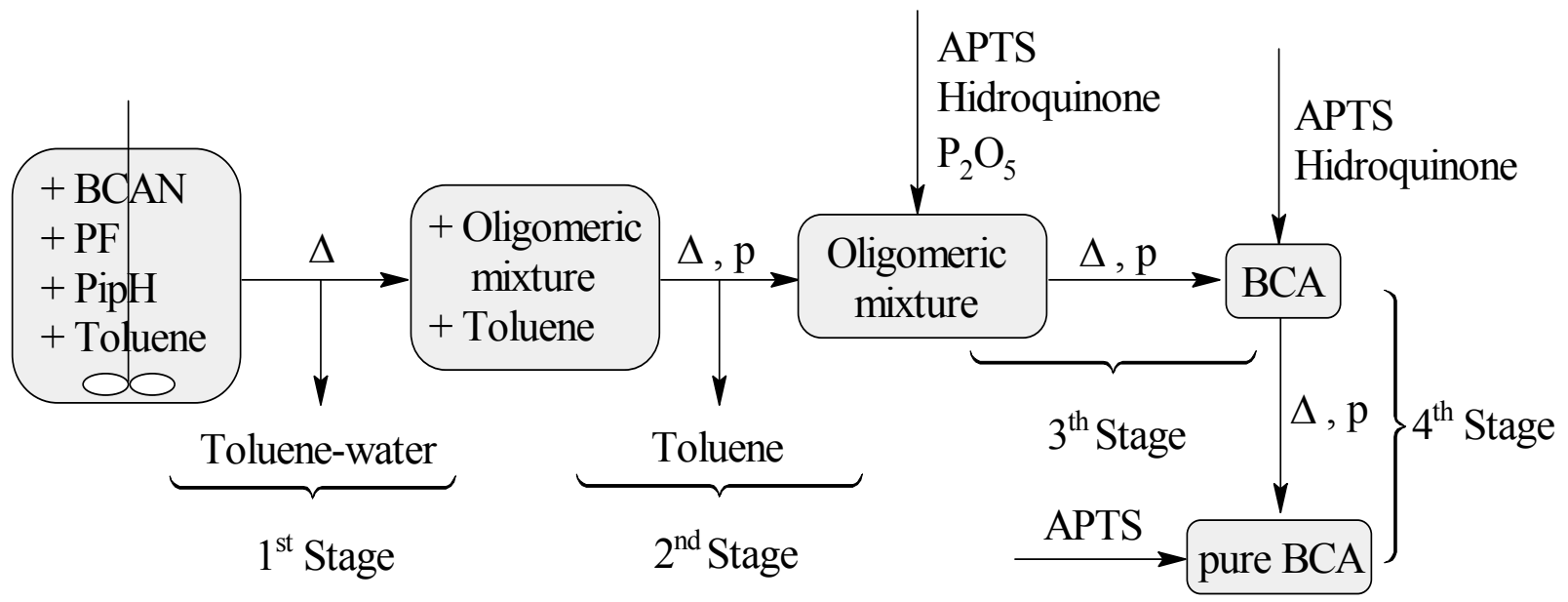

It is necessary to emphasize that comparing the second process (using a microwave oven) with the first one, some stages are avoided. This means that the first and the second stage come together (without stirring and reduced pressure), and the fourth stage is totally eliminated (Figure 2). The reason for this is because it is possible to obtain the final product with the same quality as in the case when using an oil bath when reaching the third stage. Therefore, when a microwave oven is used, only two stages are needed: toluene-water extraction and oligomers pyrolysis. 
Figure 2. Direct synthesis of BCA assisted by microwave irradiation (MW).

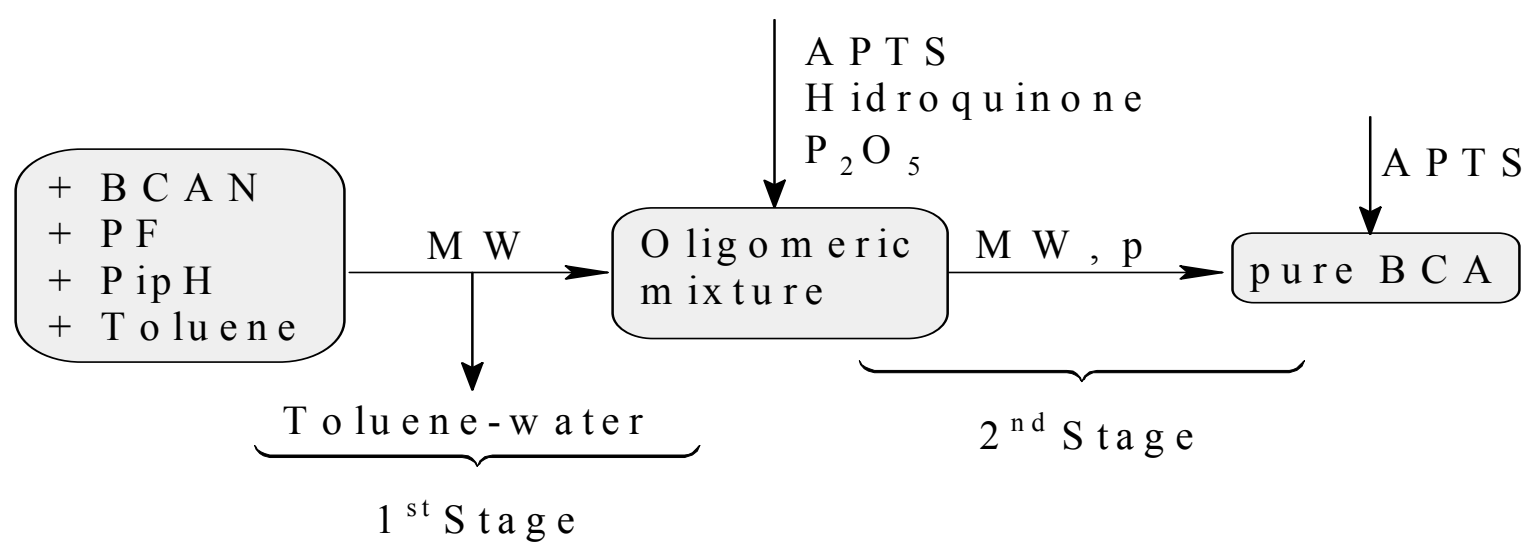

Table 1 indicates that the reaction time was reduced by a factor of 3-5 in the "direct synthesis" assisted by a microwave, in comparison with an oil bath heating, while the yield did not change significantly.

The oligomers obtained by Knoevenagel condensation were separated and purified in the "indirect synthesis" to depolymerize them by reducing the pressure using an oil bath or a microwave oven. The results are shown in Table 2. The reaction time was reduced, as in the case of "direct synthesis", but there has not been a favorable change in the yield when microwave irradiation was used.

Table 2. Results of BCA indirect synthesis (depolymerization stage).

\begin{tabular}{cccc}
\hline Heating Source & Exp. & Time (min) & Yield (\%) \\
\hline & 1 & 75 & 81 \\
Oil bath & 2 & 58 & 76 \\
& 3 & 65 & 65 \\
Mean values & & $\mathbf{6 6} \pm \mathbf{9}$ & $\mathbf{7 4 \pm \boldsymbol { 8 }}$ \\
\hline Microwave & 1 & 40 & 85 \\
oven & 2 & 37 & 72 \\
& 3 & 51 & 50 \\
Mean values & & $\mathbf{4 3} \pm 7$ & $\mathbf{6 9} \pm \mathbf{1 8}$ \\
\hline
\end{tabular}

The decrease in the reaction times caused by the use of microwave irradiation is a known fact in organic synthesis, and our results are not an exception. Concerning the yields, it is necessary to make a distinction between the corresponding steps of BCA syntheses [Equations (1) and (2)]. Water and BCA are produced in the first step, but the BCA polymerizes in situ. The second stage, the pyrolysis, is the reason why the mean global yield was $67 \%$ (oil bath) and 65\% (microwave oven) in the "direct synthesis". It was possible to verify that the thermic degradation yield of the pure oligomers in "indirect synthesis" using an oil bath and a microwave oven was similar to that obtained by "direct synthesis" (Table 2). This means that, the monomer yield is independent of the heating method. It depends on the degradation product characteristics. According to Chorbajiev et al. [21]: "the thermal degradation of low molecular poly(cyanoacrylates) is a chain process, starting at the ends of polymer chains. Volatile monomeric alkyl- $\alpha$-cyanoacrylates are formed and the product of degradation is the corresponding dialkyl- $\alpha, \alpha^{\prime}$-dicyanoglutarate, which decomposes at higher temperatures". The use of 
microwave irradiation does not change this behavior and it indicates that the yield cannot be higher than that reported in Tables 1 and 2.

\section{Experimental Section}

\subsection{General}

Paraformaldehyde, phosphorus pentoxide and acetone (Panreac, Barcelona, Spain), toluene (QUINSA, D.F., Mexico), piperidine hydrochloride (Acros Organics, Geel, Belgium), monohydrated p-toluene sulfonic acid (APTS), and tetrahydrofuran (THF) (Merck Schuchardt OHG, Hohenbrunn, Germany), hydroquinone Analar (BDH Chemicals Ltd, Poole, England), and ethanol (96\%) (national production) were used without further purification. $n$-Butyl cyanoacetate (Probus, Barcelona, Spain) was distilled previous to its use. The Fourier transform IR spectra were measured using a JASCO FT/IR-4100 spectrometer and KBr tablets. ${ }^{1} \mathrm{H}-\mathrm{NMR}$ spectra were obtained at $250 \mathrm{MHz}$ using a Bruker 250 Avance NMR spectrometer with tetramethylsilane as reference. Microwave radiation was carried out using a microwave Milestone's START System. The BCA synthesis occurs fundamentally in two steps (Equations (1) and (2)). To check the reproducibility of the methods, three experiments were carried out applying both heating sources in the cases of "direct" and "indirect synthesis".

\subsection{Direct Synthesis of BCA Using an Oil Bath}

n-Butyl cyanoacetate $(50 \mathrm{~mL}, 0.3517 \mathrm{~mol})$, paraformaldehyde (11.689 g, $0.3 \mathrm{~mol})$, piperidine hydrochloride $(0.3 \mathrm{~g}, 0.002 \mathrm{~mol})$ and toluene $(37 \mathrm{~mL}, 0.3 \mathrm{~mol})$ were mixed in a three-neck round-bottom flask. The mixture was heated to about $130{ }^{\circ} \mathrm{C}$ under stirring, while distilling out the water and toluene. When the distillation stopped, the mechanical stirring was removed and the rest of the water-toluene mixture extracted under reduced pressure. The reaction ended after about $75 \mathrm{~min}$, when distillation stopped. The formed water was measured. Phosphorus pentoxide (1.4218 g, $0.01 \mathrm{~mol})$, hydroquinone $(0.4405 \mathrm{~g}, 0.004 \mathrm{~mol})$ and APTS $(0.4517 \mathrm{~g}, 0.002 \mathrm{~mol})$ were then added to the product, which was pyrolyzed for one hour at $109^{\circ} \mathrm{C}$ between $0.15-1 \mathrm{~mm} \mathrm{Hg}$. Hydroquinone $(0.1767 \mathrm{~g}, 0.002 \mathrm{~mol})$ and APTS $(0.0961 \mathrm{~g}, 0.0005 \mathrm{~mol})$ were then added to the obtained monomer, which was purified by distillation. APTS $(0.02 \mathrm{~g}, 0.0001 \mathrm{~mol})$ was added to the final product $(36 \mathrm{~mL}, 67 \%)$. The distillation equipment used in the last two stages had been previously treated with a $20 \%$ APTS solution. Figure 1 shows all these stages.

$B C A$ : IR (KBr): 3124, 2960-2878, 2235, 1735, 1612, 1461, 1283-1187, $1386 \mathrm{~cm}^{-1}$. ${ }^{1} \mathrm{H}-\mathrm{NMR}$ (acetone- $\left.\mathrm{d}_{6}, 250 \mathrm{MHz}\right): \delta 0.96\left(3 \mathrm{H}, \mathrm{m}_{3}, J=7.23 \mathrm{~Hz},\left(\mathrm{CH}_{2}\right)_{3}-\mathrm{CH}_{3}\right), 1.44\left(2 \mathrm{H}, \mathrm{m}_{6}, J=8.03 \mathrm{~Hz}\right.$, $\left.\left(\mathrm{CH}_{2}\right)_{2}-\mathrm{CH}_{2}-\mathrm{CH}_{3}\right), 1.72\left(2 \mathrm{H}, \mathrm{m}_{5}, J=7.76 \mathrm{~Hz}, \mathrm{CH}_{2}-\mathrm{CH}_{2}-\mathrm{CH}_{2}-\mathrm{CH}_{3}\right), 4.29\left(2 \mathrm{H}, \mathrm{m}_{3}, J=7.23 \mathrm{~Hz}\right.$, $\left.\mathrm{O}-\mathrm{CH}_{2}-\left(\mathrm{CH}_{2}\right)_{2}-\mathrm{CH}_{3}\right), 6.63(1 \mathrm{H}, \mathrm{s},=\mathrm{CH}), 7.06(1 \mathrm{H}, \mathrm{s},=\mathrm{CH})$.

\subsection{Direct Synthesis of BCA Assisted by Microwave}

The same quantities of reactants used in the previous synthesis were mixed in a round bottom flask coupled with a Dean-Stark apparatus. The mixture was irradiated in a multimode microwave oven with 200, 250 and $650 \mathrm{~W}$ providing temperatures of 90,100 and $200{ }^{\circ} \mathrm{C}$, for 5,15 and $4 \mathrm{~min}$ 
respectively, when distillation of the water-toluene azeotrope ended. The formed water was then measured. The Dean-Stark apparatus was replaced by reduced pressure distillation equipment, which had been previously treated with an APTS solution. The pyrolysis was performed for $15 \mathrm{~min}$ at $200{ }^{\circ} \mathrm{C}$ with $700 \mathrm{~W}$ at $17 \mathrm{~mm} \mathrm{Hg}$ (see Figure 2). The monomer thus obtained (39 mL, 72\%) did not require any purification, since it exhibited the same appearance and sticking power as the pure monomer obtained using an oil bath. Its ${ }^{1} \mathrm{H}-\mathrm{NMR}$ and FT-IR spectra displayed the same signals reported above.

\subsection{Indirect Synthesis of BCA Using an Oil Bath and a Microwave Oven}

In this procedure, we used the oligomeric mixture obtained in the BCA "direct synthesis" (at the end of the second stage when using an oil bath and at the end of the first step in the case of using a $\mathrm{MW}$ ). The oligomeric mixture was dissolved in THF, precipitated in water and dried. The purified $n$-butyl polycyanoacrylate (PBCA) was analyzed by FT-IR and ${ }^{1} \mathrm{H}-\mathrm{NMR}$ spectroscopy. Then, PBCA (50.2818 $\mathrm{g}, 0.3283 \mathrm{~mol}$ relative to the monomer unit) was mixed with phosphorus pentoxide (1.3682 $\mathrm{g}$, $\left.10^{-2} \mathrm{~mol}\right)$, hydroquinone $(0.4108 \mathrm{~g}, 0.004 \mathrm{~mol})$ and APTS $(0.4045 \mathrm{~g}, 0.002 \mathrm{~mol})$. The mixture was pyrolyzed for $66 \mathrm{~min}$ when an oil bath was used and $34 \mathrm{~min}$ in the case of microwave irradiation. The yields were $81 \%$ for an oil bath and $72 \%$ for microwave.

PBCA: IR (KBr): 2962-2874, 2248, 1748, 1464, 1384, $1253 \mathrm{~cm}^{-1} .{ }^{1} \mathrm{H}-\mathrm{NMR}$ (acetone-d6, $\left.250 \mathrm{MHz}\right): \delta$ $0.98\left(3 \mathrm{H}, \mathrm{m},\left(\mathrm{CH}_{2}\right)_{3}-\mathrm{CH}_{3}\right), 1.52\left(2 \mathrm{H}, \mathrm{m},\left(\mathrm{CH}_{2}\right)_{2}-\mathrm{CH}_{2}-\mathrm{CH}_{3}\right), 1.76\left(2 \mathrm{H}, \mathrm{m}, \mathrm{CH}_{2}-\mathrm{CH}_{2}-\mathrm{CH}_{2}-\mathrm{CH}_{3}\right), 2.73$ (2H, m, $\mathrm{CH}_{2}$ backbone), $4.28\left(2 \mathrm{H}, \mathrm{m}, \mathrm{O}-\mathrm{CH}_{2}-\left(\mathrm{CH}_{2}\right)_{2}-\mathrm{CH}_{3}\right)$.

\section{Conclusions}

BCA was synthetized using microwave radiation and an oil bath as heating sources. The best synthetic method was "direct synthesis" assisted by microwaves, because yields were acceptable $(65.3 \% \pm 5.9 \%)$, reproducibility was good, and the reaction times were greatly reduced in comparison with the conventional oil bath heating. In addition to this improvement, it is important to emphasize that the use of microwaves is more straightforward and much safer than an oil bath.

\section{Acknowledgments}

Financial support was from the University of Havana and from the Charite Universitaetsmedizin Berlin. We gratefully acknowledge the important technical assistance of Jorge García González from ICIDCA (Cuba).

\section{Author Contributions}

Yaquelin Ramos Carriles: The main person who made all experiments and processed all the obtained results. Ricardo Martínez Sánchez and Rubén Álvarez Brito: They conceived and designed the study. Elayma Sánchez Acevedo and Paola Rodríguez Domínguez: Students who worked at the laboratory under scientific management of Yaquelin Ramos Carriles. Wolf-Dieter Mueller: Scientific adviser. 


\section{Conflicts of Interest}

The authors declare no conflict of interest.

\section{References}

1. Anonymous. Super Glue. Available online: http://web.mit.edu/invent/iow/coover.html (accessed on 22 June 2010).

2. Dadas, B.; Alkan, S.; Cifci, M.; Basak, T. Treatment of tripod fracture of zygomatic bone by n-2-butyl cyanoacrylate glue fixation, and its effects on the tissues. Eur. Arch. Otorhinolaryngol. 2007, 264, 539-544.

3. Voon, L.W.; Chua, C.N.; Hanson, R. The use of n-butyl cyanoacrylate (indermil) in lateral tarsorrhaphy. Arch. Ophthalmol. 2004, 122, 279-281.

4. Cantasdemir, M.; Adaletli, I.; Cebi, D.; Kantarci, F.; Selcuk, N.D.; Numan, F. Emergency endovascular embolization of traumatic intrarenal arterial pseudoaneurysms with n-butyl cyanoacrylate. Clin. Radiol. 2003, 58, 560-565.

5. Lo, G.-H.; Lai, K.-H.; Cheng, J.-S.; Chen, M.-H.; Chiang, H.-T. A prospective, randomized trial of butyl cyanoacrylate injection versus band ligation in the management of bleeding gastric varices. Hepatology 2001, 33, 1060-1064.

6. Grisdale, J. The use of cyanoacrylates in periodontal therapy. J. Can. Dent. Assoc. 1998, 64, 632-633.

7. Romero, I.L.; Malta, J.B.N.S.; Silva, C.B.; Mimica, L.M.J.; Soong, K.H.; Hida, R.Y. Antibacterial properties of cyanoacrylate tissue adhesive: Does the polymerization reaction play a role? Indian J. Ophthalmol. 2009, 57, 341-344.

8. Jee, Y.; Ho, J.; Jong, H.; Min, B.; Chan, J.; Ki, S.; Yong, H.; Sung, M. Endoscopic hemostasis using n-butyl-2-cyanoacrylate for massive gastric bleeding durng endoscopic transgastric drainage of pancreatic pseudocyst. Dig. Endosc. 2011, 23, 326-327.

9. Reukov, V.; Maximov, V.; Vertegel, A. Proteins conjugated to poly(butyl cyanoacrylate) nanoparticles as potential neuroprotective agents. Biotechnol. Bioeng. 2010, 108, 243-252.

10. Joshi, S.A.; Chavhan, S.S.; Sawant, K.K. Rivastigmine-loaded plga and pbca nanoparticles: Preparation, optimization, characterization, in vitro and pharmacodynamic studies. Eur. J. Pharm. Biopharm. 2010, 76, 189-199.

11. Huang, C.Y.; Lee, Y.D. Core-shell type of nanoparticles composed of poly((n-butyl cyanoacrylate)co-(2-octyl cyanoacrylate)) copolymers for drug delivery application: Synthesis, characterization and in vitro degradation. Int. J. Pharm. 2006, 325, 132-139.

12. Ardis, A.E.; Akron, O. Preparation of Monomeric Alkyl $\alpha$-cyanoacrylates. U.S. Patent 2,467,926, 19 April 1949.

13. Meier, E.A.; Ray-Chaudhuri, D.K.; Schoenberg, J.E. Process for the Manufacture of Methyl Cyanoacrylate. U.S. Patent 5,455,369, 3 October 1995.

14. Sailhan, V.; Schue, F.; Eloy, R.; Giral, L. Highly Pure Alkyl 2-cyanoacrylates. EP 0895987 B1, 31 March 2004. 
15. Jain, S.; Nagi Reddy, B.; Sambasiva Rao, K.; Neeliah, G. Microwave assisted synthesis of indole substituted alkenes using knoevenagel condensation reaction and their antibacterial activity study. E-J. Chem. 2010, 7, 543-551.

16. Mallouk, S.; Bougrin, K.; Laghzizil, A.; Benhida, R. Microwave-assisted and efficient solvent-free knoevenagel condensation. A sustainable protocol using porous calcium hydroxyapatite as catalyst. Molecules 2010, 15, 813-823.

17. Mogilaiah, K.; Prashanthi, M.; Reddy, G.R.; Reddy, C.S.; Reddy, N.V. Microwave assisted knoevenagel condensation using sodium fluoride and lithium chloride as catalysts under solvent-free conditions. Synth. Commun. 2003, 33, 2309-2312.

18. Varma, R.S. Solvent free organic synthesis using supported reagents and microwave irradiation. Green Chem. 1999, 1, 43-55.

19. Balalaie, S.; Nemati, N. Ammonium acetate-basic alumina catalyzed knoevenagel condensation under microwave irradiation under solvent-free condition. Synth. Commun. 2000, 30, 869-875.

20. Mitra, A.K.; De, A.; Karchaudhurin, N. Solvent-free microwave enhanced knoevenagel condensation of ethyl cyanoacetate with aldehydes. Synth. Commun. 1999, 29, 2731-2739.

21. Chorbadjiev, K.G.; Novakov, P.C. Study of the thermal degradation of poly(alkyl $\alpha$-cyanoacrylate)s. Eur. Polym. J. 1991, 27, 1009-1015.

Sample Availability: Samples of the compounds $n$-butyl cyanoacrylate and poly ( $n$-butyl-cyanoacrylate) are available from the authors.

(C) 2014 by the authors; licensee MDPI, Basel, Switzerland. This article is an open access article distributed under the terms and conditions of the Creative Commons Attribution license (http://creativecommons.org/licenses/by/3.0/). 